\title{
Implementing 5D BIM on construction projects: Contractor perspectives from the UK construction sector
}

\begin{abstract}
Purpose: This paper reports on primary research findings that sought to investigate and analyse salient issues on the implementation of 5D BIM from the UK contractor perspective. Previous research and efforts have predominantly focused on the use of technologies for cost estimation and quantity take-off within a more traditional-led procurement, with a paucity of research focusing on how 5D BIM could facilitate costing within contractor-led procurement. This study fills this current knowledge gap and enhances the understanding of the specific costing challenges faced by contractors in contractor-led projects, leading to the development of 5D framework for use in future projects.
\end{abstract}

Design/Methodology/Approach: In order to develop a fully detailed understanding of the challenges and issues being faced in this regard, a phenomenological, qualitative based study was undertaken through interviews involving 21 participants from UK wide construction organisations. A thematic data analytical process was applied to the data to derive key issues and this was then used to inform the development of a 5D-BIM Costing framework.

Findings: Multi-disciplinary findings reveal a range of issues faced by contractors when implementing 5D BIM. These exist at a strategic, operational and technological level which requires addressing successful implementation of 5D BIM on contractor-led projects adhering to Level 2 BIM standards. These findings cut across the range of stakeholders on contractor-led projects. Ultimately, the findings suggest strong commitment and leadership from organisational management is required to facilitate cost savings and generate accurate cost information.

Practical Implications: This study highlights key issues for any party seeking to effectively deploy 5D BIM on a contractor-led construction project. A considerable cultural shift towards automating and digitising cost functions virtually; stronger collaborative working relationship relative to costing in design development, construction practice, maintenance and operation is required. 
Originality/Value: By analysing findings from primary research data, the work concludes with the development of a 5D BIM costing framework to support contractor-led projects which can be implemented to ensure that 5D BIM is successfully implemented.

Key Words: Building Information Modelling (BIM), BIM Level 2, 5D BIM, Costing Framework, Contractor-Led Project

\section{Introduction}

For 170 years, Quantity Surveying (QS) practice has been an integral profession within the UK construction industry and has since undergone several changes within the industry (Cartlidge, 2011; Ashworth and Hogg, 2007). Conventionally, the QS practice is mainly associated with cost estimating and cost planning, production of bill of quantities (BoQs), interrogation of tender processes and documentation, procurement input, payments, construction cost control advice, valuation preparation, contractual claims and final accounts. However, changes in procurement strategies, along with developments in the construction sector have expanded the role and responsibilities of QS to cover whole lifecycle costing, value management and decision drive, risk analysis and resolution, project and construction management, facilities management, contractual disputes and litigation (Ashworth and Hogg, 2007). Construction suppliers traditionally determine project cost, requirements and material quantities by performing manual takeoffs, interpreting data manually while completing costing tasks, a process integrated with potentials for human error (RICS, 2015). Traditionally, a CAD drawing is scanned and manually interpreted to calculate quantities that make up building cost (Pittard and Sell, 2016). This is in contrast to digital measurement software that allows users to strip a building model of its elements then analyze and examine individual designs in isolation for visual takeoff. The use of the Building Information Modelling (BIM) process and associated technologies is having a profound impact on the construction sector. This is particularly evident in the field of QS, where the use of 5D (Cost) BIM has been demonstrated to have the potential to lead to more reliable project budgets and enhanced cost planning and estimating (Bryde et al., 2013).

This study is focused within the domain of 5D BIM and particularly in the area of contractor led costing. This is because there is no research focus hitherto on how 5D BIM could facilitate costing in a contractor-led procurement projects. Contractor-led projects are still grappling with the error-prone traditional way of generating cost information which in most cases has defeated project objectives, destroyed feasibility investigation that informed project investment and overall, undermined project success (Mitchell, 2012; Smith, 2014; Chuan and Sheng, 2017). However, within the 5D BIM process, digital construction information flow 
allows contractors, employers and the project team to generate accurate cost and essential estimating information with model element attributes like size, area, object family type, and productivity projections (Davies and Barnes, 2015). According to McCuen (2008) estimators with an adequate BIM understanding can benefit from the 5D BIM function and automatic quantification, by creating quicker estimates, whilst having a greater understanding of the likely cost influences of design decisions (Deutsch, 2011; Goucher and Thurairajah, 2012). Taihairan and Ismail (2015) suggested that there are six factors which affect the accuracy of using BIM for cost estimating; project information, project characteristics, team requirements, client requirements, contract requirements and external factors.

Recent studies by Mayouf et al., (2019) have identified that the role of QS is still unclear in the BIM Level 2 process. This lack of clarity, particularly in the area of contractor led projects is problematic for the successful exploitation of $5 \mathrm{D}$ BIM as a tool to foster increased cost management. From a process perspective it was noted that often the QS is not involved as an integrated part of the BIM process with Crowley (2013), whilst Monteiro and Martins (2013) observed that prevailing QS practice appends object properties in the estimating tool for takeoff suitability. With this in mind it is imperative that the implementation of 5D BIM in contractor led projects is clarified to ensure consistency and complete integration into the Level 2 BIM process.

Building on the foregoing, the aim of this study was to identify salient areas in the current implementation of 5D BIM and subsequently build a framework to allow contractors to fully utilise BIM for more effective 5D costing. By undertaking a critical analysis of research in the field of BIM and its current use in costing followed by semi-structured open-ended interviews with practitioners, the $5 \mathrm{D}$ BIM Cost Framework (5D-CF) will allow contractors to focus to improve communication, mitigate contingencies, minimise sequential conflicts that could translate to risks, uncertainties and risks with impact on final project cost.

\section{Prevailing 5D BIM Research}

One key area where BIM has been purported to provide a significant amount of benefit is allowing a more automated quantity take off (QTO) from the 3D model. The use of BIM within a project will lead to less effort being required for quantity take off as more becomes automated from the 3D model (RICS, 2014; Goucher and Thurairajah, 2012). However, others are more hesitant at the promises of the process due to the design models being unsuitable for QTO (Aram et al., 2014). The issue of automated quantity take off has received attention from researchers and is also an issue reported in industry based research. 
Cheung et al., (2012) discussed multi-level cost estimation and how this can be developed automatically from the 3D model. Focused on the conceptual design stages of a construction project, the proposed tools automatically extract data based on the New Rule of Measurement (NRM) format and provide the ability to deal with multiple levels of detail of the geometric model and thus provide more defined cost estimates as the design of a project develops. Wu et al., (2014) noted that the level of detail of a model and the level of information can have a significant impact on quality of the cost estimate and this is further supported by Mayouf et al., (2019). The issue of the level of geometric data required to produce more accurate cost estimates is also considered by Monteiro and Martins (2013) who also discussed some issues surrounding automated extraction of quantities from the 3D BIM, in particular noting that the QTO process cannot be fully automated due to the model's inability to provide an 'accurate representation' of the building. It is noted that there is a fine balance to be had between the level of graphical detail of the model needed to produce accurate quantities and the usability of existing software tools as the data sets become more complex. These issues surround the use of $5 \mathrm{D}$ within the realms of QTO and therefore cannot be relied upon for detailed cost estimates (Wang et al., 2014). Aram et al., (2014) discussed the development of a knowledge based approach to implementing QTO from a Building Information Model. Noting that the geometric model itself often does not contain the correct level of detailed information to instantly automate the QTO process, this study therefore discusses the development of a knowledge base, which allows rules to be applied to objects to develop knowledge about the product and how it can be quantified. Rajabi et al., (2015) also concurred with this approach and solve the issue of lack of model detail by allowing the user / estimator to take off where available and also add additional detail within the BIM authoring environment using logic-based reasoning.

Wijayakumar and Jayasena (2013) highlighted that whilst there are a range of tools available to automate the QTO process from BIM, the data that is derived is not always accurate or in the correct format. Citing examples of extracting linear wall lengths as an example, the wall can be measured from the centerline or the outside thus proving differing area calculations. If unchecked during an automated process this can present substantial inaccuracies in the costing further downstream in the process. However, Whang and Min (2016) claimed that using BIM, the results of the QTO are more accurate when compared to those undertaken via a traditional manual approach. Whilst an interesting response to the issue of accuracy, the study was focused purely on building frames and thus the results could be isolated when compared with a more holistic take off from a complete facility. 
From a technological point of view, Kim and Park (2016) noted that using the automated quantity take off can lead to overestimation due to model accuracy, which can cause problems. A suggested solution to this is early collaboration of the QS within the BIM process. Smith (2016) also noted issues surrounding automated take off by practitioners emphasizing that often the quality of the documentation was the biggest cause of problems in implementing automated methods. This is leading to a lack of trust in the cost based data derived from 5D BIM based on information reliability (Kulasekara et al., 2013). Early integration and constant collaboration of the QS into the project (Popov et al., 2010) and particularly the modelling aspect would allow input into the model development to ensure fitness for purpose and ensure that a reliable BIM database is available for cost estimates and cost management by the industry (Ismail et al., 2016).

Mitchell (2012) noted that whilst cost estimation is critical to any construction project, very often the concept of 5D BIM is purely seen as an approach to digitally take off quantities from models. This study notes that in following this approach, definitive costs are not derived until later in the design / modelling process, no real time cost plan data is derived and fed into the design process and this still leaves the cost aspect as a separate entity which is contrary to the fully collaborative multi-disciplinary focus of BIM. Ma and Liu (2014) proposed the development of a system that can automatically acquire construction information from a BIM data set and then subsequently use this in order to underpin construction cost estimation. Lee et al., (2014) further explained the development of an ontology based method to derive work items. The ontology approach utilized and IFC and xml approach to develop work items, which can then form part of the take-off procedure to develop a full bill of quantities. At the moment this approach was limited specifically to tiling activities however the approach was scalable.

Smith (2014) highlighted that within the industry context, practitioners identified several issues which are hindering the implementation of 5D BIM. The quality of the Model, the ability to automatically take off quantities, lack of compatibility between software and the sharing of cost data were amongst some of the issues cited in respect to current approaches to 5D BIM implementation. This work was based on the review of the industry in Australia, however other studies such as (Plebankiewicza et al., 2015) have highlighted similar issues in Poland in addition to noting that a lack of formalised classification systems in this region is also an issue in the application of 5D.

Tatt et al., (2016) identified the requirement of change in culture and current practices are required in order to manage the implementation of BIM within commercial Quantity 
Surveying practices. Using Kotters 8 stage change model as a mechanism to drive change in Malaysia, it was proposed that the process begins with creating a sense of urgency for the implementation of 5D BIM. With this in mind it could be argued that in several countries where government initiatives have driven BIM, this aspect has been provided. However, quite often barriers are still in place that prevent proliferation of 5D usage. In many cases, these barriers are cultural, whereas other researchers such as Frei et al., (2013) have suggested that technological advances such as those presented by BIM threaten to reduce the role of the QS which could further compound this cultural issue. In a review of QS professional practice in South Africa, Monyane and Ramabodu (2014) noted that whilst 5D is not widely used in the industry, a large number of those polled accept the potential benefit to managing cost throughout a project. However, professionals still observed that issues could arise from legal challenges and there was still some who believed that it could threaten the viability of the QS profession. The issue of cultural change within an organisation is also discussed by Sattineni and Macdonald (2014) who noted that during a case study of 5D implementation in a US based organisation, reluctance to embrace a new methodology was evidence in addition to a lack of drive from the client side. The lack of client demand was also highlighted by Zhou et al., (2012) who focused on the plight of SME's within the UK and Smith (2016) from an Australian perspective. This noted that at the company level demand, resource and training were key barriers to 5D BIM implementation but at project level, again highlight the issue of technological integration between tools and interoperability (Kim and Park, 2016). Alongside company level demand, training for professionals is also a critical issue to ensure company implementation is appropriate and consistent (Keat, 2013).

In a survey of practitioners within the New Zealand Quantity Surveying profession, Stanley and Thurnell (2014) reported that collaboration is deemed to improve when using BIM but many are less convinced that the application of $5 \mathrm{D}$ will lead to more efficient quantity take off or more efficient generation of cost plans. There is suggestion by those in the industry that a lack of software compatibility is an issue as is the lack of protocols for object coding within models and a lack of standard for use of 5D BIM implementation. Boon and Prigg (2012) also found that digital tools for QTO were not used in a New Zealand context but also that no systematic approach to coding is an issue when BIM is implemented.

Mitchell (2012) therefore suggested that costing and 5D is built in to the project from concept stage by building in elemental cost data into the lower level of detail BIM objects. Taihairan, and Ismail (2015) supported this approach noting that BIM requires a richer level of information at the early design / concept stage to allow more accurate cost estimates. It was also noted that the sharing of information underpinned by the philosophy of BIM would 
improve cost estimation at the early stage. The QS will therefore need to engage in the BIM process early in order to fully utilize the data available for early cost estimation. Popov et al., (2010) endorsed this concept by presenting a computer aided evaluation system to allow construction cost to develop as the project progresses through design into the lifecycle management of the asset. Managing cost throughout a construction project lifecycle is critical and often, as reported earlier, $5 \mathrm{D}$ BIM is focused on the cost estimation stage of a project. Lu et al., (2016) argued that where BIM has been used for cost management, it has primarily focused on the outflow of cash during a project, however the actual outflow is not taken into account during 5D - leaving out many issues such as retention. The study argues that in order to be fully effective, a 5D model should include for inflow and outflow during the simulation.

Smith (2016) noted that one of the key issues surrounding cost management is the modelling standards for BIM, and how these impact cost managers. These are often overcome through the development of collaborative working relationships with project designers, however this is ad-hoc and there is not consistent approach for this. Mayouf et al., (2019) highlighted level of detail (LOD) as key consideration, as is the issue of the modelling of existing buildings and it calls for a global BIM standard to support cost management. Mitchell (2012) noted that post construction cost data can still be utilized for the life cycle management of a facility by incorporating cost data (minus construction cost information) into the as-built model in preparation for the operation and asset management process.

\section{Current challenges of 5D BIM implementation}

Whilst the above demonstrates that 5D BIM is attracting a substantial amount of research across a range of topics, there are still a number of fundamental challenges reported. The following are some of the key issues that provide a greater understanding of the prevailing problems faced during the implementation of 5D concepts. They include Level of Development (LODt), Standards for coding, lack of 5D BIM protocols, and Upskilling Existing QS Workforce.

\section{Level of Development (LODt)}

Level of Development (LODt) is the degree to which the element's geometry and attached information have been produced which can impact on the degree of reliability of the project team members on the model information (project data) (BIMFORUM, 2013; RICS 2015). Level of Development, as defined in the UK PAS1192 documents, is a combination of Level of Detail (LOD) - amount of graphical information included in the model element and Level of Information (LOI) - non-graphical information (such as spatial, specifications, performance, 
certifications, workmanship, standards etc). According to Kell and Mordue, (2015), there is far greater need for common, aligned geometric and information and the resultant information output at various workstages must be fit for uses such as quantification parameters and digital measurement. A more structured approach for 5D BIM implementation and understanding utilising a structured level of detail/information for cost information output in a contractor led procurement is required (O'Brien et al., 2014; Harrison and Thurnell, 2015; Mayouf et al., 2019).

\section{Standards for Coding}

One key issue that arose from a review of existing work in the BIM field focuses on the lack of standardized coding methods within the BIM Environment. This is because BIM model information creation reflects set parameters and different formats of software vendors impacting on data quality, accuracy and reliability of extracted quantities (Thurairajah and Goucher, 2013; Harrison and Thurnell, 2015; Kim and Park, 2016; Mayouf et al., 2019). From a design point of view within the UK, the Uniclass standard from the NBS is the most prevalent method of coding objects during the design stages of a construction project (NBS, 2016). This supports most aspects of construction elements; however, it is focused on the design aspect and there is no specific requirement at the moment to integrate the costing coding mechanisms within BIM during the design phase. This leads to limited implementation of 5D BIM due to unclassified and non-integrating coding systems. Smith (2016) noted inconsistency in modelling standards leading to practices conforming to varying methods to arrive at estimates. This again establishes data-risk and quantification inaccuracies. Therefore, standardisation of coding system is required to ensure data quality, accuracy and reliability (Kim and Park, 2016). In particular, the New Rules of Measurement (NRM suite) needs to be fully integrated into BIM process from an early stage of the design to support cost estimation from the initial concept stage throughout the life cycle of the project.

\section{Lack of $5 D$ BIM Protocols for industry implementation}

The BIM Execution Plan (BEP) is vital in delivering information uniformity from project inception. The information generated is project specific, reflecting the Employer's Information Requirements (EIRs) and developed in conjunction with all project participants. The level of detail (graphical data) expected to be delivered at each workstage is largely defined and incorporates the ownership of each building element. All UK-centric developed project standards are with a single purpose of building up confidence, that design development, workstage outputs and project collaboration can be uniformly delivered. With advanced degree of "NBS Digital Toolkit" establishment, the QS and Cost Managers is expected to 
gain a good level of understanding towards digital cost information development and efficiencies in overall project lifecycle creating ultimate commonality across the industry.

Developing an industry protocol for information delivery and checks will activate means of confirming compliance against a set of project defined deliverables, more coordinated datarich information, aligned LODs and LOls standards - driving efficiencies in the design, construction, and operation of built assets and increasing reliability on information quality (Mitchell, 2012; Mayouf et al., 2019). It is a good practice to define information requirement at each workstage throughout the design and construction phase for greater project and cost efficiency. Whilst the QS and Cost Managers can deploy LODs and LOls as workstage baselines, or check mechanisms to confirm compliance of various agreed workstage outputs, there is limited formal information regarding $5 \mathrm{D}$ costing protocols within the current BEP structure. Therefore, the approach can be further enhanced across disciplines to confirm the LODs and LOls agreed requirements against each building element at various workstages for cost information.

Through the use of a specified document such as a BEP, it is imperative for the QS and cost managers, in collaboration with the design team, to regulate information uniformity at each stage of the digital plan of work (Mayouf et al., 2019). Adopting a consistent early defined object naming protocol (like NRM object descriptors) allows successive developments in the model to align cost comparisons through the cost plan stages as well as benchmark costs across projects against held data (RICS, 2014). Presently, there is a lack of development of $5 \mathrm{D}$ costing frameworks, protocols or standards integrated into existing BIM protocols, strategies, frameworks and plan of work such as Royal Institute of British Architects' (RIBA) plan of work, 2013 (Wong et al., 2014; RIBA, 2013). The development of BIM is moving extremely rapidly but how the $5 \mathrm{D}$ BIM process is embedded within the design, construction and maintenance functions is not defined. There is yet no established 5D BIM standardised framework or protocol to facilitate digitalised automated measurement functions - tailored to influence and impact construction industry practice towards automating and digitising cost management practices enabling generation of accurate cost information.

\section{Upskilling Existing QS Workforce}

Low adoption of Level 2 BIM among cost professionals is blamed generally on issues of skill uptake, challenges on BIM education and training and lack of awareness of capabilities of BIM application towards quantity surveying and commercial management practices (RICS, 2015, Wong et al., 2014). The inclusion of BIM within a range of professional academic benchmarks have led to the inclusion of the concepts, philosophies and technical knowledge 
of the BIM process being included in curricula. However, this is somewhat ad-hoc at the present time based on previous research (Underwood et al, 2015). In particular, there is little reference to how those involved with the cost and 5D element of BIM should engage through existing curricula. Yong, et al., (2008) and Bataw, et al., (2014) stated that the lack of upskilling of the commercial management workforce with BIM knowledge is generating substantial constraints in BIM implementation. Consequently, for the sector to develop the next generation of QSs' and Cost Consultants, which contribute to the implementation of digital strategies within their respective organisations, more is needed to formalize the delivery of 5D both with existing and future courses (Fox and Hietanen, 2007; Dean, 2007; Bataw et al., 2015; Smith, 2016). In addition, the collaborative nature of BIM also requires a shift in the teaching and delivery of all construction courses to ensure that subjects such as cost estimation and cost management are not taught in isolation but are seen as an integral part of the construction process and delivered via a collaborative mechanism.

In addition to teaching the philosophies, students currently engaging in academia and those already within the industry have a need to be upskilled in the use of the latest tools and technologies available. Camps (2008) and Ojo et al., (2015) argued to enable professionals to do more in less time, construction education with teaching curriculum designed to integrate digital innovative strategies and capabilities, should be effectively structured in training students who potentially become practice professionals.

\section{Research Methodology}

Since cost is a key parameter for effective construction management process, it is essential to develop a costing framework and protocol that deploys 5D BIM to overcome these inefficiencies - integrating BIM processes and tools into current design and construction practices particularly in a contractor-led project. Building on the above literature and the challenges identified from prevailing research, this work sought to build on existing knowledge of the implementation, use and issues surrounding 5D BIM in contractor led projects through a qualitative research approach. Semi-structured open-ended interviews were undertaken with a total of 21 practitioners within the industry (Figure 1). These represented stakeholders across the construction supply chain covering Tier 1 (design consultants and main contractor organisations - principal supplier - with direct contract with the client and/or employer) and Tier 2 (design, constructors and suppliers organisations, with a sub-contract with Tier 1 organisations to perform specific tasks - ranging from small and large scale commercial projects to mid-sized infrastructure projects) contractor's organisation, client organisation, sub-contractors/fabricators (offsite manufacturers), cost consultants (multinationals) and cost consultants (SMEs). Each of the participants had a 
minimum of 2 years and a maximum number of 40 years experience within the construction industry and a mean number of 11 years of experience. Also of note that during the interviews it was established that all of the interviewees had experience of using both $2 \mathrm{D}$ and 3D data on the projects they had worked on. All participants had experience of working on contractor led construction projects and their particular experiences in this regard were requested to help inform this research.

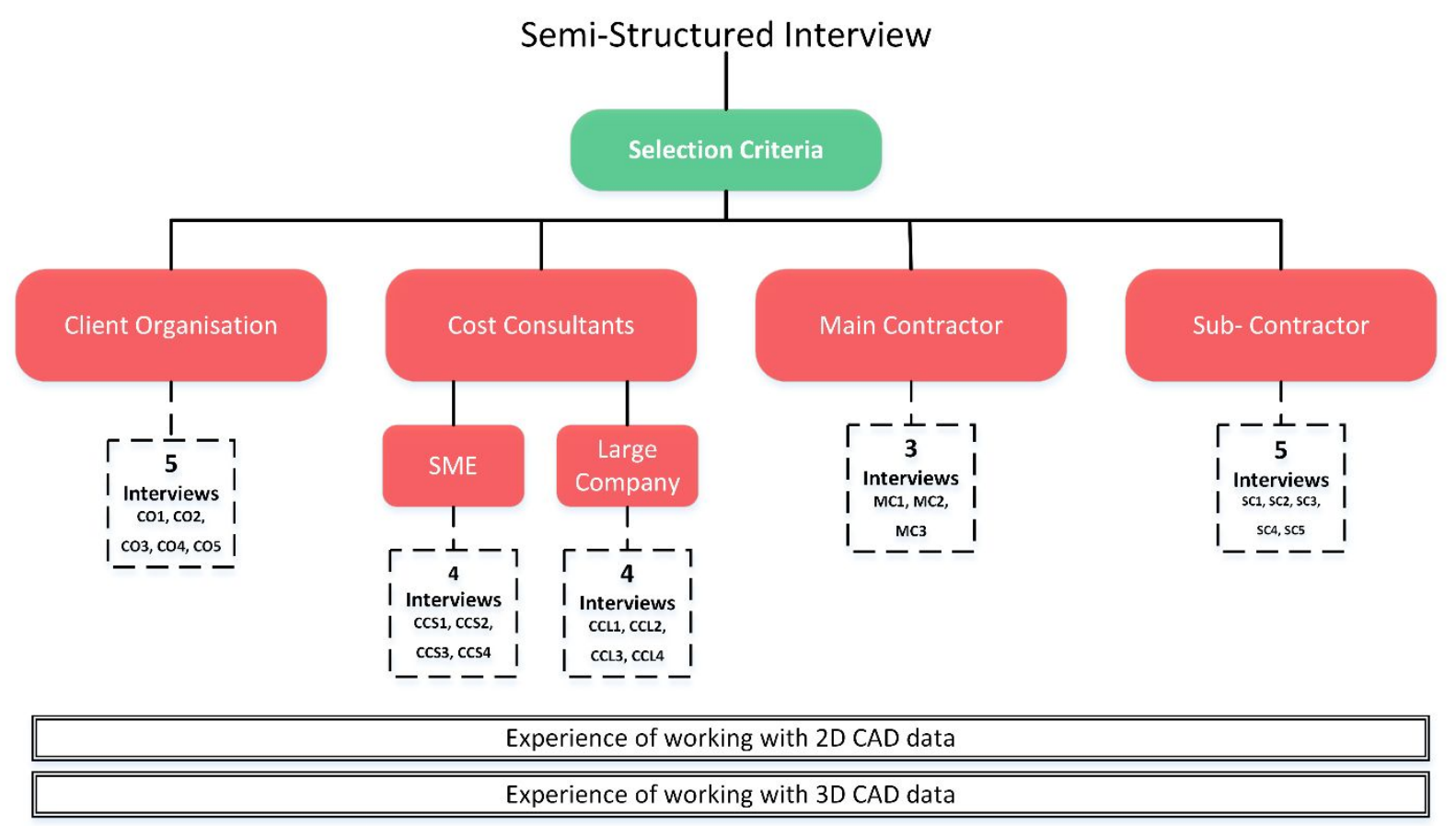

Figure 1: Breakdown of Interview Participants

A phenomenological approach was utilised as this looks at the context or settings that influenced how the participants experienced the phenomenon and is referred to as imaginative variation or structural description (Moustakas, 1994). Further, the study adopts a purposive sampling technique to select target participants for the research based on set criteria of relevant experience and knowledge of BIM and 5D BIM implementation (Denscombe, 2010; Saunders et al., 2016). This sampling strategy was used as it could offer informants who could provide data to help in the understanding of the development of $5 \mathrm{D}$ BIM framework facilitating costing in contractor-led projects. In the recruiting process, set predefined inclusive and exclusive criteria were used to select participants for the interview. One of the basic criteria for being a participant in the interviews was basic or in-depth experience in executing BIM in contractor led projects, designing with BIM digital capabilities, exposure to virtual projects, linking of model information to generate non-geometric data, involvement with digital quantification with respect to cost estimation (5D BIM) and finally, the willingness of the participants to contribute in the interview session. 
Collected data was transcribed, analysed using thematic analysis and interpreted. This allowed the identification of significant statements and developed textural and structural descriptions into an exhaustive description of the invariant structure of that which is experienced. The textural and structural descriptions aided the composite description that presents the 'essence' of the phenomenon called the essential, invariant structure (or essence).

The analysis for this study was done using thematic analysis in order to provide an orderly and logical approach to analysing qualitative data (Saunders, Lewis and Thornhill, 2016). The analysis involved coding of the qualitative data to identify themes or patterns for further analysis related to research questions (Saunders et al., 2016). The research philosophical assumptions which in this case is subjective was reflective in data interpretation with a consideration that thematic approach is a standalone analytical technique. According to Creswell (2009), regardless of the qualitative methodology used in the analysis, a common process to qualitative data analysis involving six steps is discernible, though the steps may not necessarily be linear. The steps are as follows: organisation, reading through the data repeatedly to get the general sense of the data (familiarisation with data), coding, using coding process to identify categories or themes and to generate description, contextualising and interpretation of the data.

As detailed previously, data for this study was collected from five facets of the construction sector covering the spectrum of construction business in the UK. The audio recordings were transcribed verbatim by the researcher before the analysis was carried out. The analysis mirrored the six steps as outlined above and was done manually. This was done by searching for themes to explore relating to research interest and questions and grouping the themes and sub-themes from the collected data.

\section{Results and Discussion}

Significant statements, sentences and important units of data extracts were highlighted and developed into clusters of meanings forming themes. The whole transcribed data set was explored for occurring and reoccurring themes, thus the bubbles used to collate themes were further represented in a tabular form and scored to both identify and select dominant themes relevant to the phenomenon under investigation. During the first iteration of the analysis, three dominant themes were identified using extracted data units, significant patterns and clusters (Figure 2). 

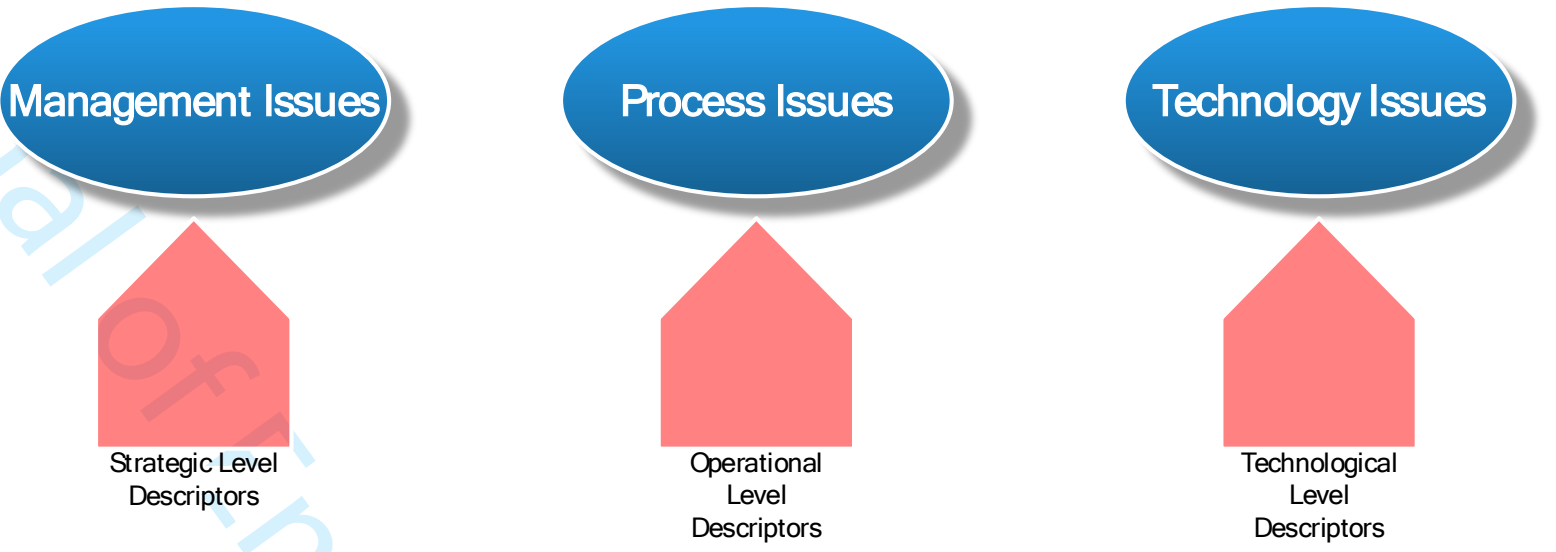

Figure 2: First iteration of dominant themes relating to 5D BIM

The initial analysis was done by engaging in reflection, identifying and using colours to highlight key words. The researcher read repeatedly through the transcribed data to get the general sense of the data (familiarisation with the data) - line by line to make sense of it and to ascertain that what has been transcribed is a true presentation of participants' responses. This helped the researcher to stay true to the data and paying attention to see what themes, relationships or patterns were emerging (Figures 3, 4 \& 5) as mentioned by Bringer, Johnson and Brackenridge (2006), while interpreting and explaining the findings. Relevant data to research interest was coded forming the foundation to the reoccurring theme across transcribed dataset. A systematic coding reflective of key phrases, research question and objectives was performed manually as earlier mentioned to categorise data with similar meanings (labelling each unit of data within a data item), generating concepts, establishing data autonomy as well as category connections. According to King (2004) software can help the researcher with complex coding schemes and coding large amount of text, however it is also important to emphasise that although computer programmes may be supportive to organise and examine large amount of data, intellectualising and conceptualising processes required for data transformation is still left to subjective human judgement (King, 2004; Thorne, 2000). This gives credit to manual coding and interpretation of coded units of data as agreed by Saunders et al., (2016). According to Ibrahim (2012) it may be better to use manual analysis in instructing data sets rather than computer based-methods. Using computer software to analyse data could help identify family of words and patterns but may not capture developing coding trend, context, and settings reflecting contextualised assumptions that is evident or underpinning the data. As 5D BIM is an emerging concept the identification of nuance statements, meanings and patterns from collected data requires intense familiarisation of transcribed data. 


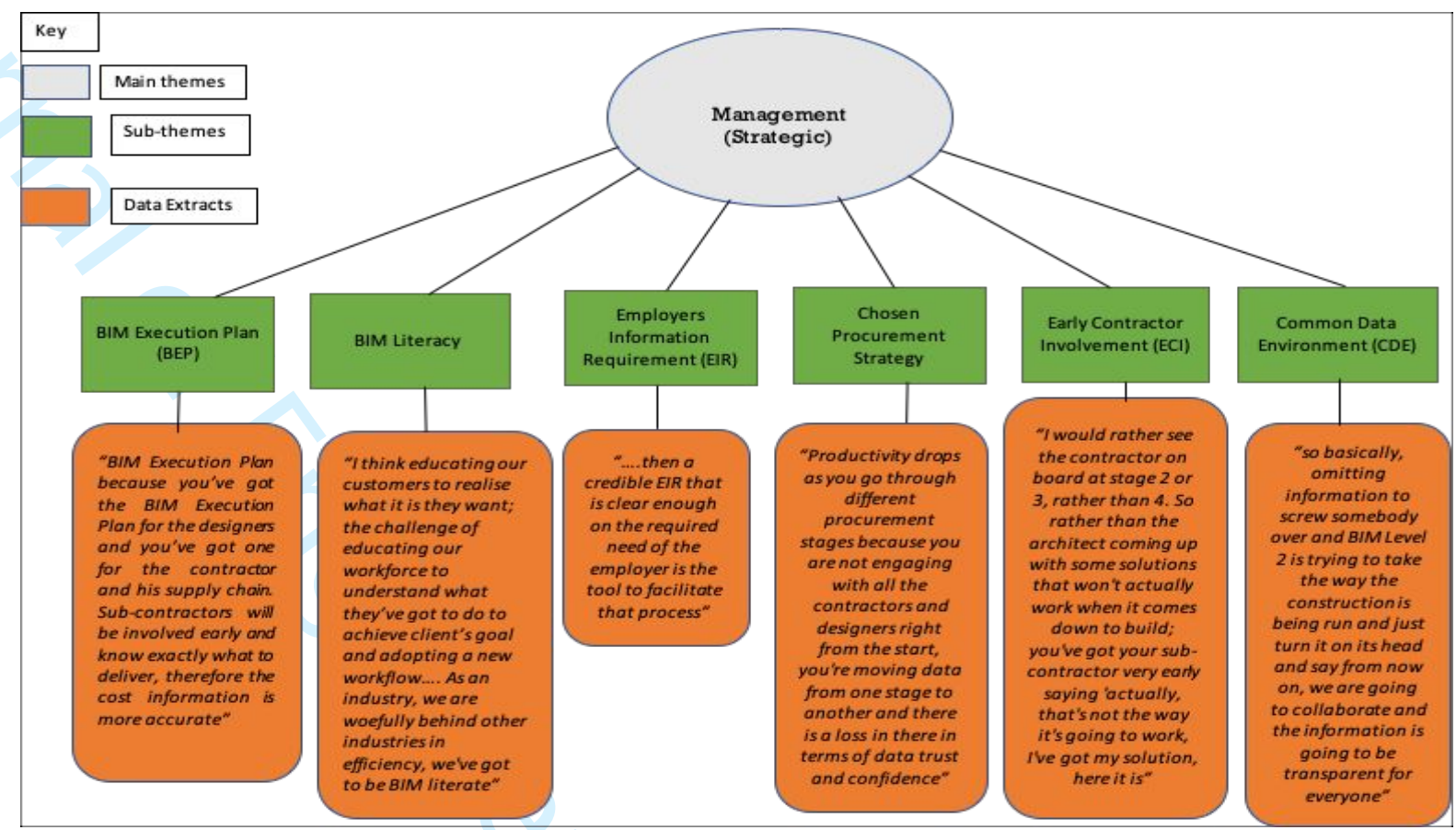

Figure 3: Identification of sub-themes 1

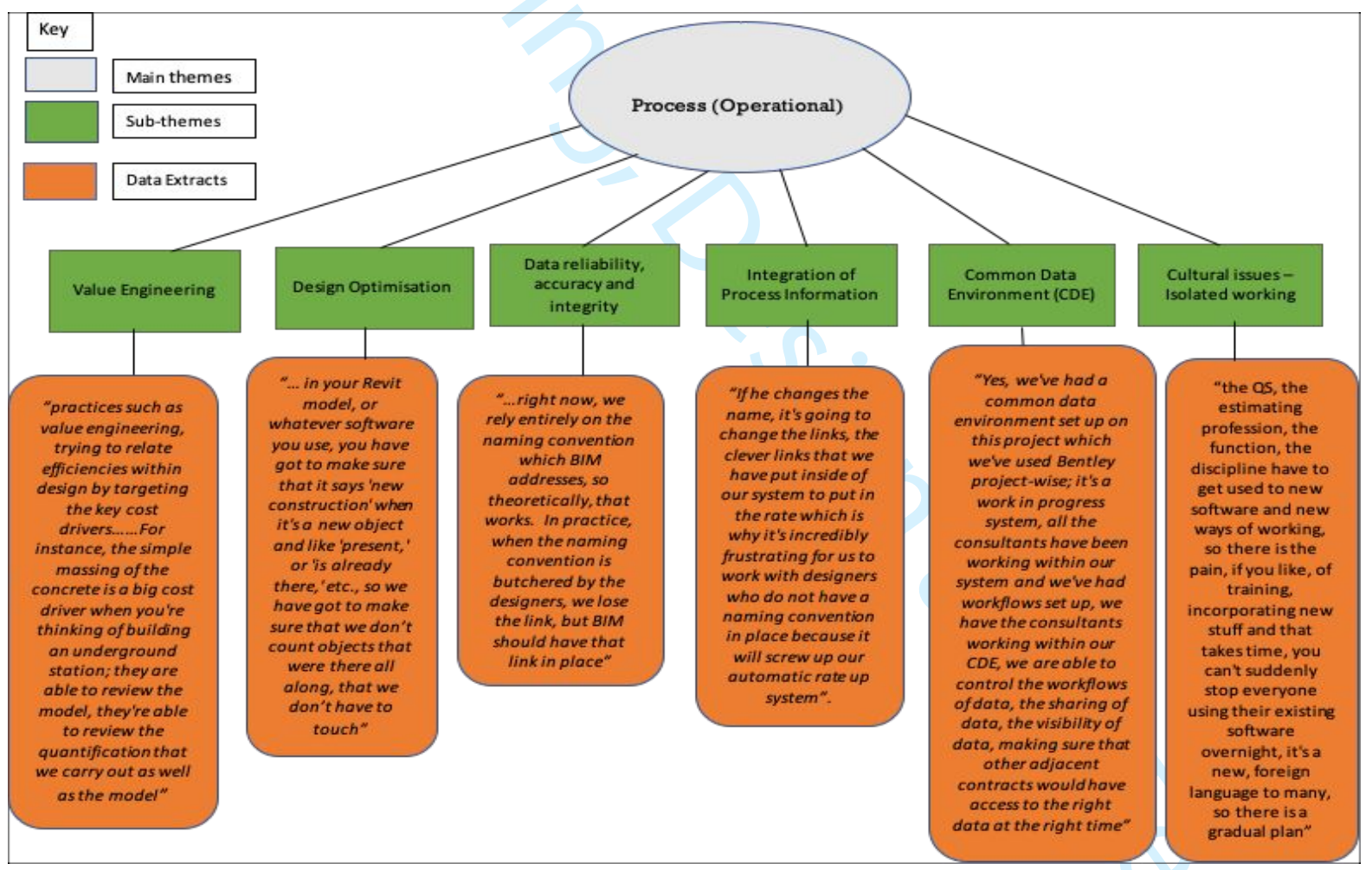

Figure 4: Identification of sub-themes 2 


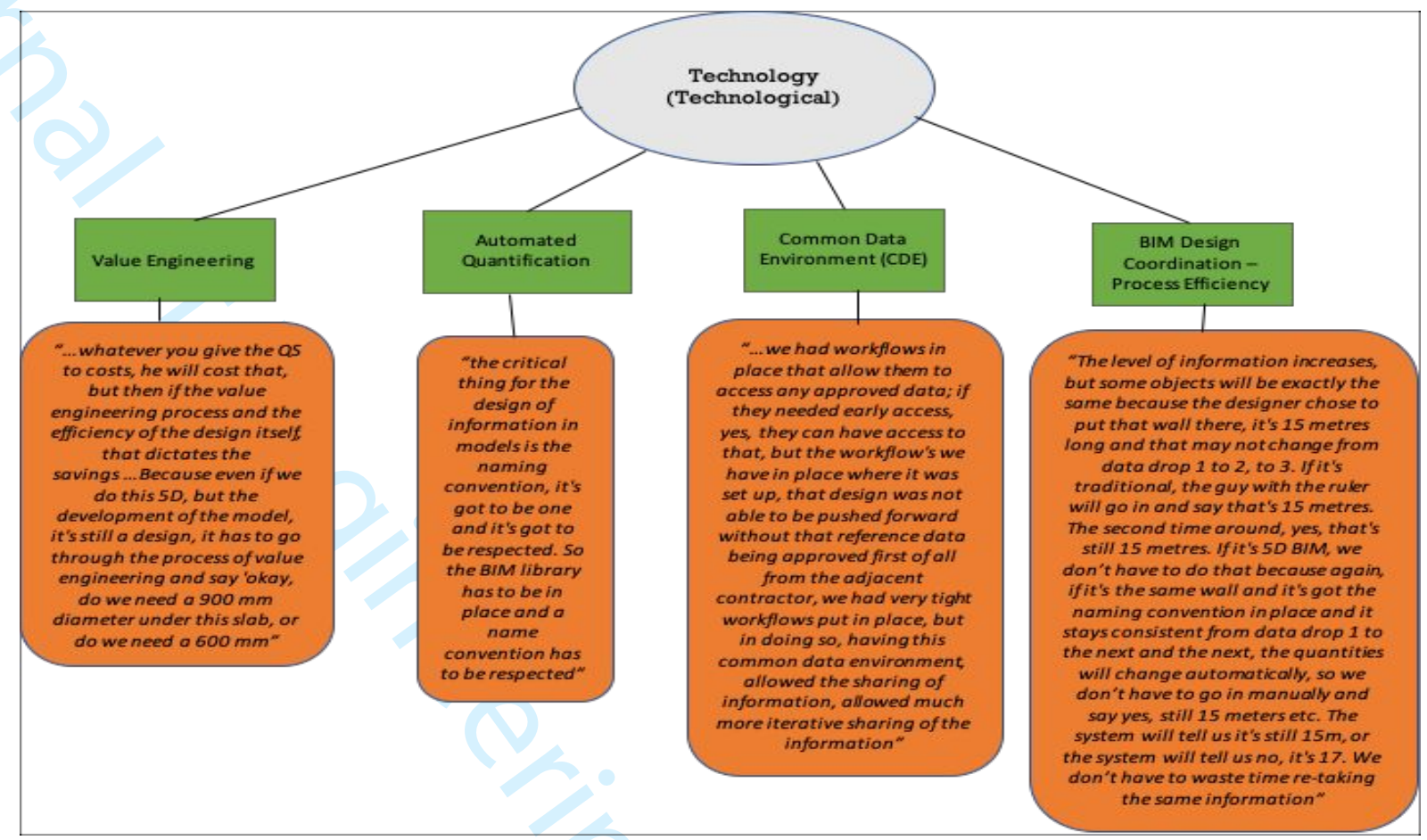

Figure 5: Identification of sub-themes 3

\section{Framework Development}

The review of relevant literatures identified some key areas around the implementation of 5D costing within the wider BIM process. It was noted that whilst areas were identified there was a gap in knowledge specifically surrounding the implementation of 5D BIM in contractor led construction projects in the UK. Building on the existing research knowledge, and the results from the semi-structured interviews a 5D BIM Costing Framework (5D-CF) was developed (Figure 6). Both literature and interview findings established the need for a 5D BIM approach to mitigate the current traditionally integrated cost estimation process, which hitherto continues to undermine the client's project objectives and outcome. The framework development is based on a contractor-led procurement as opposed to traditional-led procurement. In a traditional project team, the design is produced and developed to a certain level of detail by a design team appointed by the client and a number of contractors tendering for the project, with an emerging successful contractor at the end of the tender process. Typically, the client is the employer here and determines requirements, decisions, objectives that influence design solutions, project budget, outputs/outcomes and other associated costs and risks except where the traditional design team is novated to the contractor together with the cost and programme risks of design work already undertaken. 
The developed 5D-CF is however focused on a contractor-led project team, where the contractor is the employer (normally in a design and build project) and influences both technical, commercial and management requirements for inclusion within tender process providing a strategic brief of what is required, when and to what standards. This entails defining cost estimation processes in conjunction with the BEP whilst requiring details and approaches to meet cost ceilings as demanded by the client and engaging all project stakeholders. In contractor-led procurement, the contractor takes full responsibility of governing both early and full appointment of the project team (Pittard and Sell, 2016). The framework is developed as informed by research particularly with this practice approach in mind where a contractor is in charge of strategic level decisions that influence staff process outputs using appropriate technology to improve workflow while increasing effectiveness, efficiency and productivity in 5D cost processes. The framework was developed with the intent to facilitate the uptake of $5 \mathrm{D}$ BIM costing processes in a contractor-led procurement project.

The framework is proposing a concept that the Strategic Level (Management) of a contractor-led project would make strategic decisions based on the outline strategic brief, assessed needs or project objectives, requirements, defined quality, timeline, 5D cost and performance benchmarks, benefits and value add (Garlick, 2016; Pennanen et al., 2011). The staff with a good understanding of the requirements of those strategic decisions work collaboratively at the operational level (Process) to implement those decisions deploying appropriate technology (Technological Level) to drive solutions (RICS, 2014), since BIM is about Management (people), Process and Technology. 


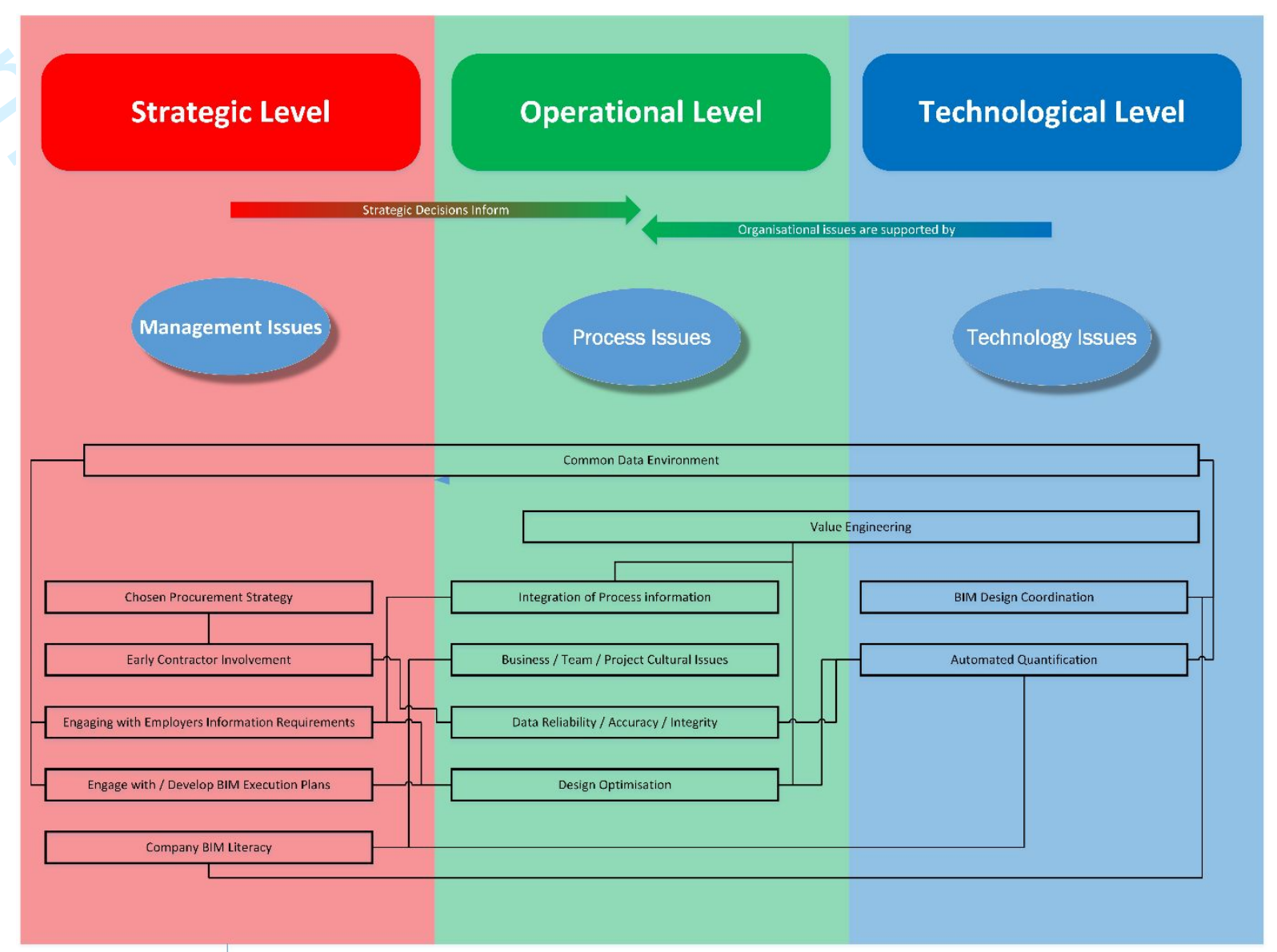

Figure 6: 5D BIM Costing Framework (5D-CF) to Facilitate Costing in Contractor-Led Project

\section{Strategic Level}

Research has shown previous studies to have focused on the technical aspects of BIM while neglecting the role or the perspective of all management levels towards enforcing a smooth implementation process, appropriate procurement strategy and clarity on project and data requirements (Arayici et al., 2012; Stasis et al., 2012). This is supported by the primary data in this study regarding contractor led projects. In particular surrounding the decision to involve contractors early in the project, one of the participants who is a BIM Strategy Manager from a client organisation noted:

"... it has to be done from the conception, or from planning stage because from a client perspective, we need to make sure we've got clarity on data, so it's not just about the physical assets, but also about what information, or what digital data we need in order to design that asset, build it and operate and maintain it at the end..." and continued further to say;

"....Procurement has always been an issue; we need to have early engagement, we need to make sure the data that's coming back we have confidence in the integrity of that data, then at least that could resolve some of the issues, but because we don't have any integrity, or we don't have 
confidence in the provenance of the data that's been delivered during the first stage, effectively, the contractors might have to start from scratch. Productivity drops as you go through different procurement stages....and there is a loss in there in terms of data trust and confidence"

In the views of the participant, going for procurement at each delivery stage gate is problematic to already defined project cost and would have negative impact on the overall project outcome. Inconsistency with procurement solutions affect data requirements set by the employer, interfered with $5 \mathrm{D}$ cost expectations and contract programmes at different stages. This created risks within the process, lack of data trust, lack of confidence and integrity in data provenance and made the whole process very inefficient. At the moment during more traditional procurement, contractors are involved at a later stage during design model development, and at this stage the benefits of contractor's vast experience and inputs within the design processes are lost.

Having a strategic management decision to involve the contractors very early on in the project and engaged in the BIM process, provides greater opportunity to add value to the process and the ability to add more valuable data to the digital model. Cost advice at the outset would influence the project at the earlier stage giving all project actors the ability to understand how to integrate cost into the early stages of project development. Providing high level cost information to the project team would provide guidance to design, build, operate and maintain facilities within stipulated budget and this was highlighted by a BIM Information Manager from a sub-contractor:

"... having our expertise at the outset stops them designing something incorrectly. So if we're talking 'where do they come in initially? It should be right at the very outset, I'd say even once the brief has been given, that's where contractors should come in".

Early Contractor Involvement and the supply chain is exclusively a management decision with positive impact on project outcome for all stakeholders. The contractors' ability to engage with the initial Employers Information Requirements (EIR) when involved early in the project should allow the integration of clients agreed programme and cost to their internal programme linking design, cost and schedule; thus supporting the development of a useful 5D BIM approach for all. This would also provide the ability for the contractor to engage with the BEP and develop a more robust approach to implement costing within the BIM process. This was highlighted by two participants, a BIM Director from a Tier 1 main contractor organisation and a Cost Consultant from an SME organisation respectively: 
“.....to harness BIM Level 2 requirements from a contractor's construction workflow viewpoint... then a credible EIR that is clear enough on the required need of the employer is the tool to facilitate that process"

"....The use of BIM is going to encourage contractor-led procurement rather than traditional. Traditional is the way things are being done right now and I think it's going to slowly transfer to $D \& B$ being the major way of doing things because it encourages the early involvement of the contractor through the transparency of information..."

A clearly defined employers' requirement facilitates well-informed decision making from the contractor and the supply chain meaning greater clarity of design information, better visual communications, and ultimately better cost efficiency. The contractor as a major player in delivering employers key project requirement with his supply chain will need to grapple with the content of EIR. If the management strategic decisions are based on how it has always been, innovative approaches coming from the supply chain and the contractor would be lost and would not offer best value for money. Participants from the research field across construction organisations agree with literature findings on EIR and reinforce vigorously the need for employers or their advisors to clearly identify what they need to be included or excluded in BIM Level 2 requirements informing EIR development and influences contractors' BEP.

\section{Operational Level}

When organisations worked in silos focusing on their own practice outputs, common standards or collaborative working offered fewer benefits. However, the advent of BIM is a game changer in terms of how project teams deliver functions and utilisation of common standards different from isolated organisation working culture drives efficiency. Common standards facilitate the automation of 5D processes and collaborative working, agreeing on certain workflow upfront on a project. The roles at the operational level would need to keep an eye on design model inputs with respect to how the QS and cost consultants visualises objects within the model enabling proper cost function and quantification automated responsibilities. The process as identified in the analysis allows all project team members (owners, architects, engineers, contractors, subcontractors and suppliers) to collaborate in a virtual environment more accurately and efficiently than the traditional process. One of the participants who is a Head of BIM from client organisation highlighted a practical narrative:

"We had a common data environment set up on this project. We have the consultants working within our CDE and we are able to control the workflows of data, the sharing of data, the visibility of data, 
making sure that other adjacent contracts would have access to the right data at the right time (any approved data). We had very tight workflows put in place and having common data environment allowed the sharing of information and much more iterative sharing of the information".

The naming convention should be captured and agreed on by the project team during the preparation of the BEP creating an efficient automated process and interrogating the efficiency of the design with clear reference to client's requirement. This should encapsulate files and layers and should be explained in detail especially its impact on export requirements at work stages and software support. Supporting this, the previous respondent noted:

"We had a document naming wizard set up in our common data environment, so the project parties could not name something incorrectly. They were forced to name something the way we wanted it named. So having that naming convention strategy in place well defined made it much more efficient and much easier for us, as a client, to do the data, but also the sharing of data with other consultants".

Model information undergoes constant refining and adjustment process to ensure project requirements and specifications including any alteration arising from design changes are reflected as accurately as possible before actual physical execution of the construction on site. Designs are constantly optimised for value improvement (value engineering), quality, aesthetics, constructability, cost (affordability), timelines and milestone schedules and a seamless flow of construction information transfer into the operation and maintenance phase. Therefore, information exchange formats need to be agreed by the project parties and the QSs and cost managers as data recipients will state what formats and versions of data is required such as IFC, PDF, DWG, DWF etc. For the Cost consultants and QSs to initiate suitable adjustments to quantities, rates, other ancillary costs and automate modifications as appropriate; compatibility issues need consideration and possible determination of tools, software and exchange formats that suits particular service delivery. Inability of the BEP to address the use of suitable software platforms would hamper information sharing and file exchange. Varying software platforms will have different implications to a QS or cost consultants. One of the participants, a 5D BIM Information Manager from a cost consultancy SME organisation highlighted this:

"We have got issues around designers using the wrong object in their 3D models. For example, a simple column is sometimes drawn on the 3D model as a wall, so instead of having a square column, the designer will put a very small wall to represent that column. If I open (the file) on 'Cost $X$ ' and without looking at the model, export or do my quantities export, I will have a wall instead of a column, but it should be a column, so it should go into two different sections in the NRM 1 cost estimate. 
There are issues when something is modelled using the wrong tool... so we've got to be careful around the designer's information because sometimes it's simply wrong..."

The 5D BIM QSs or cost manager would need to understand how the measurement tool will process the building elements and objects in a CDE to avoid compromising data integrity which one of the participants referred to as "loss of data intelligence" - that is comprising the integrity of the electronic data being exchanged. Exchange workflows in a collaborative working process should be tested early in the design process to curb a later compromise of data integrity. The associated issues relating to the variance of the level of details and information especially between design disciplines at different project stages/work stages should also be noted. The 5D BIM QSs or cost consultant should compare the output required with the provided model detail at each work stage when measuring as supplementary quantification may be needed.

One last issue the study discovered under operational level is project cultural issues. To exploit full 5D BIM capabilities and benefits towards a more accurate and quicker cost information generation, contractors and the supply chain, QS practices and cost consultants are required to re-evaluate and re-engineer their business processes. One of the participants, a BIM Director in a Tier 1 Main Contractor organisation highlighted this:

"....the QS, the estimating profession, the function, the discipline have to get used to new software and new ways of working. The pain of training, incorporating new stuff takes time, you cannot suddenly stop everyone using their existing software overnight, it is a new foreign language to many, there is a gradual plan... The software is already there and available, that is not a blocker, it is the people, culture and training"

"Cultural conservatism" or resistance to change is a strong barrier to 5D BIM implementation. Digital technological competencies acquired by emerging QSs and cost consultants is perceived as threats by more established QS personnel in construction organisations and this is constituting even more stronger barrier towards 5D BIM adaptation. This concurs with Smith, (2014) who highlights the skill threat of the new cost professionals to the established ones. The study also found out that client and contractor organisations have an existing bespoke cost model, specific cost coding system of design elements/objects and lots of other existing intelligent database that drives their business processes. 


\section{Technological Level}

The primary data also identified appropriate use of BIM technology as an advantage for a seamless enforcement of employers and project requirements, ability to collate, process, exchange, manage and share information from a common data environment. According to Eastman et al., (2011), digital models with 3D data only without object attributes, models with no support behaviours, models with multiple 2D CAD component files which are to be combined to define a building or models with no capacity to automate design changes on adjacent design elements are not BIM models. Therefore, it becomes imperative to make good use of BIM technological tools for digital automation, 5D component quantification, integration of process information and design process efficiency.

Skilled employees with good understanding of digital process use appropriate technological tools to automate cost estimate tasks enabling value improvement while optimising results. Quantities are generated directly from the model through automation for cost estimation. As such QS job performances are much more enhanced as compared with the traditional procedures; it's far more accurate and quicker. To demonstrate the far reaching positive impact of 5D BIM process against the traditional conventions. One of the participants, a cost consultant noted that:

"We actually ran a test in the office; we were on a specific project and were given the usual $2 D$ drawings and the 3D model. It took half a day to take off all the steel structure - 1,000 tons of steel in half a day. It took us 15 minutes to take off the information (from the BIM) and we arrived at 1,150 tons, so because our system is strictly based on the quantities within the model, we can't be wrong, so we for sure have the right result for the steel structure though. (The other method) was wrong by 15 per cent..."

The conventional manual interventions or interpretation of data breeds risks of inconsistency and error in costing activities whereas 5D BIM has capabilities to quantify accurately while reducing error margins. BIM with multi-dimensional capabilities and the information sharing abilities enables all parties involved in a construction project to visualise the model content from a single dimensional image and provides detailed designed elements and quantification for QS use (Mena et al., 2010).

\section{Conclusion and Recommendation}

The implementation of 5D BIM processes is providing strategies to prevent further cost overrun that burdens project budget from design preliminary to operations and maintenance as digital cost estimates evolves. This study set out to fully understand the process with 
respect to contractor-led projects and provide a framework to allow the supply chain utilise BIM for more effective 5D BIM costing processes. Literature revealed current challenges in 5D BIM implementation and subsequently qualitative data was collected from a cross section of actors within contractor-led projects through semi-structured open-ended interviews. Generated thematics from data analytical process was used to develop 5D BIM costing framework (5D-CF) which identified key issues to be considered when fostering a practice shift towards automating and digitising cost functions; consolidating stronger collaborative working relationship as contribution to knowledge.

The developed constructs within the framework allow the contractor and the supply chain to fully utilise BIM for effective 5D BIM costing as an integral part of the evolving design, construction, operation and maintenance work stages. Strategic issues, operational issues and technological issues are three main identified areas to be addressed by those working in the project team on contractor-led projects. Within these areas, a total of 16 interrelated elements should be addressed in order to ensure the successful implementation of 5D BIM across the lifecycle of a project. Educating and equipping contractors and the supply chain workforce with adequate skillset particularly the QS, estimators, cost managers and cost consultant professionals will see the design inputs drive cost certainty. Leveraging on the management decision to follow processes to generate the most accurate and reliable cost information and implementing it using the right technological tool is critical to effective $5 \mathrm{D}$ costing activities. Going forward for existing and future projects, it is noted that it is imperative to engage workforce at the process level with a good understanding of 5D costing process; implementing processes and tools from early concept design stages through to post construction using relevant technological tool kits.

The research study recommends a development of a 5D BIM cost protocol with a possible impact to the UK construction industry practice and further industry evaluation of the costing framework (5D-CF). This will support project stakeholders in streamlining design, construction and operational process with detailed but not exhaustive information on the requirement of $5 \mathrm{D}$ implementation in a construction BIM project. This means it could be modified for suitability to fulfil $5 \mathrm{D}$ project requirements in various successive projects. $A$ proper application of the recommended protocol to tender process should generate reliable and accurate cost information during design, construction and operational phase in a contractor-led procurement project. 


\section{References}

Ashworth, A. and Hogg, K. (2007), Willis's Practise and Procedure for the Quantity Surveyor, $12^{\text {th }}$ ed., Oxford: Blackwell Publishing Ltd.

Aram, S., Eastman, C. and Sacks, R., (2014), "A knowledge-based framework for quantity takeoff and cost estimation in the AEC industry using BIM". In The 31st International Symposium on Automation and Robotics in Construction and Mining pp.1.

Arayici, Y., Egbu, C. and Coates, P. (2012), "Building Information Modelling (BIM) Implementation and Remote Construction Projects: Issues, Challenges, and Critiques", Journal of Information Technology in Construction, Vol. 17 pp.75-91.

Barnes, P. and Davies, N. (2015), BIM in Principle and in Practice, $2^{\text {nd }}$ ed., Institute of Civil Engineers (ICE) Publishing.

Bataw, A., Kirkham, R. and Papadaki, M. (2015), "Incorporating Building Information Modelling within the Construction Curriculum in the UK", ARCOM Doctoral Workshop on Construction Education in the New Digital Age. CIB W089 Building Research and Education

Building Information Modelling Forum (BIMFORUM) (2013), "Level of Development Specification for Building Information Models" Available at https://bimforum.org/wpcontent/uploads/2013/08/2013-LOD-Specification.pdf Accessed [14-19-2019)

Bringer, J. D., Johnson, L.H., and Brackenridge, C.H. (2006), "Using Computer-Assisted Qualitative Data Analysis Software to Develop a Grounded Theory Project Field Methods", Vol. 18 No.3, pp.245-266.

Bryde, D., Broquetas, M. and Volm, J.M. (2013), "The project benefits of building information modelling (BIM)", International Journal of Project Management, Vol. 31 No.7, pp.971980

Camps, H.L. (2008), "BIM, Education and the Global Education", Journal of Building Information Modelling, Spring 2008, pp.33-37.

Cartlidge, D. (2011), New Aspects of Quantity Surveying Practice. Oxon: Spon Press.

Cheung, F.K., Rihan, J., Tah, J., Duce, D. and Kurul, E. (2012), "Early stage multi-level cost estimation for schematic BIM models", Automation in Construction, Vol. 27, pp.67-77.

Chuan, T. M. and Sheng, L. X. (2017), "Cost Overrun of Iconic Buildings: Managing Construction Cost Through Building Information Modelling - A Conceptual Paper", Congress Proceedings for the 21st Annual Pacific Association of Quantity Surveyors Congress, Vancouver, BC, Canada. Available at www.paqs2017.com [Accessed 30/10/2019)

Creswell, J. W. (2009), Research Design: Qualitative, Quantitative, and Mixed Methods Approaches. SAGE Publications

Crowley, C. (2013), “Identifying Opportunities for Quantity Surveyors to Enhance and Expand the Traditional Quantity Surveying Role by Adopting Building Information Modelling", Paper presented at the CITA BIM Gathering, Dublin Ireland. 
Dean, R. (2007), "Building Information Modeling (BIM): Should Auburn University Teach BIM to Building Science Students?" Graduate Capstone, Department of Building Science, Auburn University

Denscombe, M. (2010), The Good Research Guide: for small social research projects.

Deutsch, R. (2011), BIM and Integrated Design: Strategies for architectural practice, Hoboken, NJ: John Wiley and Sons

Eastman, C., Teicholz, P., Sachs, R. and Liston, K. (2011), BIM Handbook: A Guide to Building Information Modeling for Owners, Managers, Designers, Engineers, and Contractors $2^{\text {nd }}$ ed., Hoboken, NJ: John Wiley \& Sons, Inc

Fox, S. and Hietanen, J. (2007), "Interorganizational use of building information models: potential for automational, informational and transformational effects", Construction Management and Economics, Vol. 25 No.3, pp.289-296.

Galick, P. (2016), “Early Contractor Involvement”, The Journal of the Chattered Institution of Civil Engineering Surveyors - Civil Engineering Surveyors, pp.31-33

Harrison, C. and Thurnell, D. (2015), "BIM implementation in a New Zealand consulting quantity surveying practice" International journal of construction supply chain management, Vol.5 No.1, pp.1-15.

Ibrahim, A. M. (2012), "Thematic Analysis: A critical review of its process and evaluation", WEI International European Academic Conference Proceedings, Zagreb, Croatia.

Ismail, N.A.A., Drogemuller, R., Beazley, S. and Owen, R. (2016), "A Review of BIM Capabilities for Quantity Surveying Practice", MATEC Web of Conferences 2016, EDP Sciences, pp. 00042.

Kell, A. and Mordue, S. (2015), "Levels of Detail and Levels of Information published in NBS National BIM Report" pp.18-25

Kim, K.P. and Park, K.S., (2016), "Implication of quantity surveying practice in a BIMenabled environment", In Pacific Association of Quantity Surveyors Congress, pp. 1-11.

King, N. (2004), Using templates in the thematic analysis of text, In Cassell, C., Symon, G. (Eds), Essential guide to qualitative methods in organisational research, pp.257-270. London, UK: Sage.

Kulasekara, G., Jayasena, H.S. and Ranadewa, K.A.T.O. (2013), "Comparative effectiveness of quantity surveying in a building information modelling implementation" In The Second World Construction Symposium, pp.101-107.

Lee, S., Kim, K. and Yu, J. (2014), "BIM and ontology-based approach for building cost estimation". Automation in Construction, Vol. 41, pp.96-105.

Ma, Z. and Liu, Z. (2014), "BIM-based intelligent acquisition of construction information for cost estimation of building projects", Procedia Engineering, Vol.85, pp.358-367.

Mayouf, M., Gerges, M., and Cox, S. (2019), "5D BIM: An Investigation into the Integration of Quantity Surveyors within the BIM Process", Journal of Engineering Design and Technology, Vol. 17 No.3, pp.537-553 
McCuen, T. L. (2008), "Scheduling, Estimating, and BIM: A Profitable Combination", AACE International Transactions, pp.1-8.

Mena, Á., López, F., Framiñan, J. M., Flores, F. and Gallego, J. M. (2010), "XPDRL project: Improving the project documentation quality in the Spanish architectural, engineering and construction sector", Automation in Construction, Vol.19, pp.270-282.

Mitchell, D. (2012), “5D BIM: Creating cost certainty and better buildings", 2012 RICS Cobra Conference, Las Vegas, Nevada USA 2012.

Mitchell, D. (2012), "The 5d Qs: Today's Methodology in Cost Certainty", Proceedings of the RICS COBRA, Las Vegas, NV.

Monteiro, A. and Martins, J.P. (2013), "A survey on modelling guidelines for quantity take offoriented BIM-based design", Automation in Construction, Vol.35, pp.238-253.

Moustakas C. (1994), Phenomenological Research Methods. Thousand Oaks, CA: Sage

National Building Specification (NBS) (2016), "National BIM Report 2016", http://www.bimforum.cl/wp-content/uploads/2017/05/BIM-Report-2016.pdf.

Ojo, A. O., Rahimian, F.P., Goulding, J. and Pye, C. (2015), "Construction Education Requirements for Achieving Level 2 And 3 BIM", ARCOM Doctoral Workshop on Construction Education in the New Digital Age, CIB W089 Building Research and Education.

Pennanen, A., Ballard, G. and Haahtela, Y. (2011), "Target costing and designing to targets in construction", Journal of Financial Management of Property and Construction, Vol.16, pp.52- 63.

Pittard, S. and Sell, P. (2016), "BIM and Quantity Surveying", Routledge: Taylor and Francis Group, London and New York

Plebankiewicza, E., Zima, K. and Skibniewski, M. (2015), "Analysis of the first Polish BIMBased cost estimation application", Creative Construction Conference 2015 (CCC2015), Procedia Engineering Vol.123, pp.405-414. Available at https://www.researchgate.net/publication/283536378 Analysis of the First Polish BI M-Based Cost Estimation Application

Popov, V., Juocevicius, V., Migilinskas, D., Ustinovichius, L. and Mikalauskas, S. (2010), "The use of a virtual building design and construction model for developing an effective project concept in 5D environment", Automation in construction, Vol.19 No.3, pp.357367.

Rajabi, M., Bigga, T. and Bartl, M. (2015), "Optimization of the quantity take-off (QTO) process for Mechanical, Electrical and plumbing (MEP) trades in tender estimation phase of the construction projects ISARC", Proceedings of the International Symposium on Automation and Robotics in Construction, Vilnius Gediminas Technical University, Department of Construction Economics \& Property, pp. 1.

Royal Institute of British Architects (RIBA) (2013), "RIBA Plan of Work 2013" [online] Ribaplanofwork.com. Available at: https://www.ribaplanofwork.com/ [Accessed 3 August, 2019]. 
Royal Institute of Chartered Surveyors (RICS) (2014), "How can Building Information Modelling (BIM) Support the New Rules of Measurement (NRM1)", London: RICS, p.23.

Royal Institute of Chartered Surveyors (RICS) (2015), "Quantity Surveying and Construction", [Accessed: 20 January, 2018]. Available at http://www.rics.org/uk/apc/pathwayguides/construction-pathway-guides/quantities-surveying-and-construction/>

Royal Institute of Chartered Surveyors (RICS) (2015), BIM for cost manager: requirements from the BIM model. 1st ed., London: RICS.

Sattineni, A. and Macdonald, J.A. (2014), "5D-BIM: A Case Study of an Implementation Strategy in the Construction Industry, ISARC", Proceedings of the International Symposium on Automation and Robotics in Construction 2014, Vilnius Gediminas Technical University, Department of Construction Economics \& Property, pp. 1.

Saunders, M., Lewis, P., and Thornhill, A. (2016), Research Methods for Business Students, 7th ed., Pearson

Smith, P. (2014), "BIM \& the 5D project cost manager", Procedia-Social and Behavioral Sciences, Vol.119, pp.475-484.

Smith, P. (2016), "Project Cost Management with 5D BIM", Procedia - Social and Behavioural Sciences, Vol.226, pp.193-200

Stanley, R. And Thurnell, D. (2014), "The benefits of, and barriers to implementation of 5D BIM for quantity surveying in New Zealand", Australasian Journal of Construction Economics and Building, Vol.14 No.1, pp.105-117

Stasis, A., Whyte, J., Stephens, E. and Dentten., R. (2012), "Building Information Modelling and Management in Infrastructure Programmes: A Scoping Study in Crossrail", In Technologies for Sustainable Built Environments EngD conference.

Taihairan, R.B.R. and Ismail, Z. (2015), "BIM: Integrating Cost Estimates at Initial/Design Stage", International Journal of Sustainable Construction Engineering and Technology, Vol.6 No1, pp.62-74.

Thorne, S. (2000), "Data analysis in qualitative research Evidence Based Nursing", Vol.3, pp.68-70.

Thurairajah, N. and Goucher, D. (2013), "Advantages and challenges of using BIM: A cost consultant's perspective", In 49th ASC Annual International Conference, California Polytechnic State University (Cal Poly), San Luis Obispo, California.

Goucher, D., and Thurairajah, N. (2012), "Usability and Impact of BIM on Early Estimation Practices: Cost Consultant's Perspective" In: Joint CIB International Symposium of W055, W065, W089, W118, TG76, TG78, TG81 and TG84, June 26th - 29th 2012, Montreal, Canada.

Underwood, J., Ayoade, O., Khosrowshahi, F., Greenwood, D., Pittard, S. and Garvey, R. (2015), "Current position and associated challenges of BIM education in UK higher education". In BIM Academic Forum. 
Whang, S. W. and Min, P.S. (2016), "Building Information Modelling (BIM) for Project Value: Quantity Take-Off of Building Frame Approach", International Journal of Applied Engineering Research, Vol.11, No.12 pp.7749-7757. Available at https://www.ripublication.com/ijaer16/ijaerv11n12_28.pdf

Wijayakumar, M. and Jayasena, H.S. (2013), "Automation of BIM quantity take-off to suit QS's requirements", The Second World Construction Symposium 2013: SocioEconomic Sustainability in Construction, $14^{\text {th }}-15^{\text {th }}$ June, Colombo, Sri Lanka, pp. $70-80$

Wong, P. F., Hafez, S., Rahim, M., and Azli, F. (2014), "Capability of Building Information Modelling Application in Quantity Surveying Practice", Journal of Surveying, Construction and Property. Available at: <http://ajba.um.edu.my/index.php/JSCP/article/view/6385> [Accessed 04/06/2019].

Wu, S., Wood, G., and Ginige, K. (2014), "A Technical Review of BIM Based Cost Estimating in UK Quantity Surveying Practice, Standards, and Tools", ITCON, Vol.19, pp.534-562

Yong, N. W. Jr., Jones, S. A. and Berstein, H. M. (2008), "Building Information Modeling (BIM): Transforming Design and Construction to Achieve Greater Industry Productivity", SmartMarket Report, McGraw-Hill Construction, New York. 